\title{
The Interpretation of HH-Index Output Value When Used As Mobile Market Competitiveness Indicator
}

\author{
Aboubacry Diallo $^{1} \&$ Gustav Tomek ${ }^{1}$ \\ ${ }^{1}$ Dept of Economics, Management and Human Sciences, Faculty of Electrical Engineering, Czech Technical \\ University, Czech Republic \\ Correspondence: Aboubacry Diallo, Dept of Economics, Management and Human Sciences, Faculty of \\ Electrical Engineering, Czech Technical University, Czech Republic. E-mail: abudiallo@yahoo.com
}

Received: February 4, 2015

doi:10.5539/ijbm.v10n12p48
Accepted: October 9, 2015

Online Published: November 25, 2015

URL: http://dx.doi.org/10.5539/ijbm.v10n12p48

\begin{abstract}
This paper aims to prove that the Herfindahl-Hirschman Index (HHI), which is widely used to describe the concentration of a given market, may not be a good competitiveness indicator as many authors assume when dealing with a mobile market. This paper shows that even if the HHI formula itself is not in doubt, but when used for a market which meets two basic criteria: it is regulated and has limited resources (the frequencies used to provide mobile service are not infinite, which implies the limitation on the number of firms in the segment), its result can be misleading. In a market segment, where the two previously mentioned conditions are met, the interpretation of an HHI output value is almost known in advance. According to the current interpretation of an HHI output value, no mobile market in the world is highly competitive, which elicits some questions.
\end{abstract}

Keywords: HHI, herfindahl-hirschman index, mobile market, market concentration, competition in mobile market

\section{Introduction}

It is important to note that this article is not intended to prove whether the HHI formula is correct or wrong, but instead it provides an analysis of a correct interpretation of an index output value for some specific markets. As already reported in literature (Rimantas Stanikūnas, 2011), the vast majority of authors dealing with market concentration would use the output as a means of defining the status of the mobile market. Hence, we aim first to look at the specificity of the mobile market before discussing the usage of the HHI when dealing with concentration in such a market. We will show later that the direct or assumed correlation between the market concentration and domination power or lack of competition may not be as direct as many authors imply. The proper usage of an $\mathrm{HHI}$ value is quite critical, since many market regulators will consider it in their decisions to approve or disapprove a merger or acquisition. In our view, there are two key characteristics that could be attributed to the mobile market:

- Its heavy regulation.

- Limitation of resources enabling a provision of services (radio frequencies).

There are also other important indicators which could hint whether a high concentration index means automatically a dominant power. Those are:

a. The cost for entering this segment is high.

b. The speed at which the technology is evolving changes the way the service is delivered and consumed.

c. The existence and the number of independent MVNOs (Virtual Mobile Network Operator) could make a big difference. From the above mentioned indicators is evident that more factors need to be taken into consideration when interpreting the HHI output for the mobile market. We will evaluate the impact of these factors on the interpretation of the HHI outputs later.

The research strategy adopted here is to look at the specificity of the market concerned to analyze the characteristics of this market and to apply the HHI output interpretation before discussing our observations. 


\section{Mobile Communication Market}

The history of mobile market evolution can help us understand the criteria that will be used to question the automatic usage of the HHI when evaluating a mobile market.

Mobile communication has evolved from the service provided initially by state-owned telecommunication companies to a segment where the presence of the state has become an exception rather than the rule. Almost in all countries, mobile service providers started as fix line telecommunication providers. With the evolution of technology together with social demand, they swiftly added mobile service offerings. Nowadays, one aspect which significantly influences our lives is mobile communication.

From another perspective, the impact of telecommunication, in general, and mobile communication, in particular, on our social and economic life was phenomenal in the last few years. But the key resources needed to enable the communication (the radio frequencies) are limited, The limitation of these resources explains why each country has a limited number of licensed mobile network operators (MNO). In Table 1, the number of MNOs in a given number of countries worldwide is illustrated.

Table 1. Number of MNOs in a given number of countries worldwide

\begin{tabular}{lllllllllllll}
\hline Numbre of MNOs & 1 & 2 & 3 & 4 & 5 & 6 & 7 & 8 & 9 & 10 & 11 & 18 \\
\hline Numbre of countries & 29 & 30 & 43 & 36 & 19 & 7 & 2 & 2 & 1 & 0 & 3 & 1 \\
\hline
\end{tabular}

Source: UIT, Txtnation.

This indicates that the number of players in this market segment is and will always be limited, and we will see later what effect this limitation has on the HHI.

As indicated in (Lucio Fuentelsaz, Juan Pablo Maicas Ã, Yolanda Polo, 2008) there were and still are debates about the best way to achieve the right balance between healthy competition and managing the frequencies which are valuable national resources that deserve a great attention. Once the frequencies for mobile services were allocated, the incumbent fix line telecommunication operators exploited their advantages, i.e. existing customer database and know-how to dominate the market from start. Hence, we could argue that a mobile communication market started either as a monopoly or quasi monopoly segment. This situation is bolstered by inertia, which leads to situations in which it was difficult for the existing mobile consumers to leave the incumbent operator(s) and switch to other rivals with a smaller presence in the market. Moreover, newcomers to the industry take the existing operator as the reference point when making their commercial decisions. As a result, the established companies reinforce their position, reducing the expected performance of new entrants. Once this argument is taken into account, one can understand why it is almost impossible to have a mobile market, where the dominant player has a share lower than $10 \%$ (this number is crucial and will be discussed below). Since the number of operators nowadays varies mostly only through a merger and acquisition, the market share of the market leader is unlikely to fall under $10 \%$.

Another important factor in the mobile market that worth mentioning is the presence of mobile virtual network operators (MVNO). Almost in all mature markets, regulations have been put in place to facilitate the entrance of MVNOs as a means of increasing competition (Aboubacry Diallo, 2014). Since the strategies of some of these MVNOs (service providers without own infrastructures) reshaped the market demand (e.g. the operator FREE managed to achieve a large market share in a very short time in France when it entered the market with an offer of "eat all you can" voice call, sms and data for $€ 20$ per month), the inclusion of these MVNOs or their exclusion in the market definition could impact the HHI output interpretation as well as the relation between the concentration and competition.

\section{Herfindahl Hirschman Index (HHI or H)}

The Herfindahl, Hirschman Index $(H)$ is a parameter indicating the competition between the firms operating in the same market and country as it provides a means of using the relationship between the number of firms and their respective market share to define the level of the concentration (implying competition). In 1950, O. C. Herfindahl proposed the index calculating the market concentration without a square root in the formula below in his thesis in 1964, Albert. O. Hirschman in his article claimed the paternity of the above mentioned formula. Hence in literature, the index is referred to as the Herfindahl-Hirschman index nowadays.

The mathematical formula for the index is: 


$$
H=\sum_{i=1}^{n} S i^{2}
$$

where

$\mathrm{i}=\mathrm{a}$ firm in a given industry ( $\mathrm{i}$ varies from 1 to $\mathrm{n}$ );

$\mathrm{n}=$ a number of firms participating in a given industry;

$\mathrm{Si}=$ each firm's market share in the considered industry.

Market share can be expressed either in percentage or in whole number. If the whole numbers (e.g. 0.25 market share) are used, the maximum value of $\mathrm{H}$ is 1 , while if expressed in percent (e.g. $25 \%$ market share), the maximum value of the index can range up to $100^{2}$, or 10,000 .

Table 2. Interpretation of the outputs of $\mathrm{H}$ value

\begin{tabular}{lll}
\hline Market definition according to the $\mathrm{H}$ output value & General interpretation & $\begin{array}{l}\text { Horizontal Merger Guide as used by US } \\
\text { competition authority } \\
\text { Justice, 2010) }\end{array}$ \\
\hline Highly competitive & $\mathrm{H} \leq 100$ & $\mathrm{H} \leq 100$ \\
Is not concentrated & $100<\mathrm{H}<1000$ & $100<\mathrm{H}<1500$ \\
Is moderately concentrated & $1000<\mathrm{H}<1800$ & $1500<\mathrm{H}<2500$ \\
Highly concentrated & $\mathrm{H}>1800$ & $\mathrm{H}>2500$ \\
\hline
\end{tabular}

The interpretation of the output indicates that the smaller the $\mathrm{H}$ value is, the less concentrated the market is, hence the more competitive it is supposed to be. This direct assumption will be discussed at the end of this paper, since $\mathrm{H}$ will always be of a high value for some specific markets.

When defining a market concentration, the HHI is the most commonly used parameter. This widespread usage may come from the simplicity of the formula combined with the easiness of the output interpretation leading to a wide criticism for such blunt usage. In Mark G. Lijesen (2004) the criticism related to the index was divided in two key aspects:

- $\quad$ The first one questions the robustness of the market definition.

- $\quad$ The second one doubts the direct relation between the concentration and market power.

Triole (1988) addressed the second part by indicating that the market concentration measures, in general, ignore other important factors determining a market power, such as the cost of entry and asymmetry in costs or demands.

This lack of unanimity on the meaningfulness of the index usage for all types of industry has led some authors to calculate a coefficient that would reflect the specificity of the addressed segment and to multiply the index as standardly calculated with this new coefficient as shown in Mark G. Lijesen (2004), when the HHI for an Oslo general practitioner market was looked at.

To address this unbalance in the interpretation of the outputs, some authors, Brown suggested using a normalized index expressed as:

$$
\mathrm{H}=1 / \mathrm{N}+\mathrm{N}^{*} \mathrm{~V}
$$

where

$\mathrm{N}=$ the number of firms in the considered market.

$\mathrm{V}=$ the statistical variance of the firm market share.

defined as:

$$
V=\frac{\sum_{i=1}^{n}(S i-1 / N)^{2}}{N}
$$


In the market, where all firms would have exactly the same share, the variance is nonexistent; leading to $\mathrm{H}$ equals $1 / \mathrm{N}$. If the number of players is constant (which is quite usual in several countries, where there is no MVNO or their impact is totally ignored when calculating HHI), then a higher variance will result in a higher index value due to a higher level of asymmetry between firms' shares.

\section{Applying the H-Index to a Mobile Market}

As already mentioned above, the mobile market has some specificity that needs to be taken into account when interpreting the $\mathrm{H}$ output value. In each mobile market, $\mathrm{H}$ will be calculated as follows:

$$
\mathrm{H}=\mathrm{S}_{1}^{2}+\mathrm{S}_{2}^{2}+\ldots \mathrm{S}_{\mathrm{n}}^{2}
$$

where

$\mathrm{S}_{1}$ is a share of the firm $1, \mathrm{~S}_{2}$ is a share of the firm 2 etc.

Table 2 indicated that for a market to be defined as highly competitive, the output value of $\mathrm{H}$ has to be inferior to 100 (assuming market share values are expressed in percentage)

As an example, we can calculate the H-index of the Czech market in 2012 based on the market share provided by the local regulator as:

$$
\mathrm{H}=24.18^{2}+39.40^{2}+36.42^{2}=3461
$$

Table 3. Czech MNOs market share in \%, HHI and R indexes

\begin{tabular}{lllll}
\hline & 2009 & 2010 & 2011 & 2012 \\
\hline Vodafone & 22.63 & 23.64 & 24 & 24.18 \\
T Mobile & 38.43 & 38.13 & 40 & 39.40 \\
Telefonica O2 & 38.94 & 38.23 & 36 & 36.42 \\
HHI index & $\mathbf{3 5 0 5}$ & $\mathbf{3 4 7 4}$ & $\mathbf{3 4 7 2}$ & $\mathbf{3 4 6 1}$ \\
$\boldsymbol{R}$ index & $\mathbf{3 7 4 0}$ & $\mathbf{3 6 9 2}$ & $\mathbf{3 7 3 1}$ & $\mathbf{3 7 1 0}$ \\
\hline
\end{tabular}

Source: Regulator's market share data is used for an index calculation. The 2012 data does not take in to account the share of the newly started MVNO.

We can see that once there is one single firm with a market share equal or higher than $10 \%$; then we may not need to calculate the H-index to define market as competitive , since the holistic interpretation of the $\mathrm{H}$ output value based on Table 2 would mean that the market could not be described as highly competitive.

$$
\mathrm{H}=100+\mathrm{S}_{2}^{2}+\mathrm{S}_{3}^{2}+\ldots+\mathrm{S}_{\mathrm{n}}^{2}
$$

If we assume a firm having a share of $10 \%$, then whatever the market share of the others firms are, the output of $\mathrm{H}$ would indicate that such a market cannot be defined as highly competitive, regardless the market shares of other players.

If we follow the same logic, no mobile market in the world would satisfy the definition of "highly competitive" based on the $\mathrm{H}$ output value interpretation in Table 2.

The reason why we come to this output is that the maximum value of $\mathrm{n}$ (in the HHI formula) is limited here (if we consider MNOs only, the number of players is likely to be less than 20, see Table 1; if we take MVNOs into consideration, the value of $n$ would not still be infinite). For every mobile market also the leading player is likely to have a share higher than $10 \%$ as explained. There are the arguments why, for every mobile market in the world, the value of $\mathrm{H}$ will be higher than 100 :

- $\quad i$ is limited (the number of players is limited).

- $\quad$ In some markets there are MVNOs that could play a key role in the market even if they might have a small impact on the H output value (MVNOs taken individually tend to have a small market share).

- $\quad$ Due to historical evolution, the major player in any selected mobile market is likely to have a market share higher than $10 \%$.

Some authors suggest using the Rosenbluth index instead of the HHI, since it is more sensitive to the number of 
firms in the market (which could be useful in the markets, where there are dozens or hundreds of MVNOs). The formula defining the Rosenbluth index is:

$$
R=1 /\left(2 \sum i S i-1\right)
$$

where

$\mathrm{Si}$ is an $i$-th competitor's market share.

$i$ is a competitor's ranking in the market, where $i$ varies from 1 to $\mathrm{n}$.

$n$ is the number of competitors in the selected market segment.

As it was done for the HHI, a different output value of $\mathrm{R}$ would indicate a different level of concentration in the ranges similar to those in Table 2:

for $\mathrm{R}<1000 \ldots$ a very low concentration.

for $\mathrm{R}=1000$ - 1800, a moderate concentration.

for $\mathrm{R}>1800$ a high level of concentration.

The calculation of $\mathrm{R}$ was shown above in Table 3: the Czech MNOs market share in \%, HHI and R indexes.

Again if we apply the argument that the number of firms in the segment is limited, we can conclude that both indexes would have the same weaknesses, except for the later which may be more indicative if there are many small players (namely MVNOs) with very small market shares. The table also shows the difference and the evolution of both indexes.

\section{Discussion}

Stanikūnas, Burinskas (2011) denoted that only $0.01 \%$ of the authors dealing with the concentration of the mobile market had presented an analysis of such a concentration. In the literature, almost all authors dealing with the mobile market use $\mathrm{H}$ mechanically to indicate a market concentration. We calculated $\mathrm{H}$ for all EU countries individually and did the same calculations for different mobile markets in different region of the globe. None of them had an index value below 1500 . Does this mean that there is no highly competitive mobile market in the world? The answer is definitely no.

Besides the two criticisms of the HHI mentioned in Section 3, we can add a third one based on the argument of market specificity. It is clear now that once a market segment meets at least the following two criteria:

- The market is regulated with a high barrier to entry.

- The key resource necessary to provide the service in a selected market segment is limited.

then a holistic interpretation of $\mathrm{H}$ output value range could provide distorted market definition. We can notice that, if the market meets the above mentioned criteria, its $\mathrm{H}$ value will be higher than 100; i.e. it cannot be defined as highly competitive if we use $\mathrm{H}$ as a sole parameter.

\section{Conclusion}

In this paper, we have shown that, while the HHI may be a useful parameter to gauge a market concentration (implying a competition level), the way the output interpretation is used could provide a distorted view on the mobile market definition. We know now that the result of $\mathrm{H}$ value will be higher than 100 before any calculation is done, which means that no mobile market is highly competitive, which is a wrong statement. This approach could be used to prove the same result for any regulated market with limited resources.

The current definition of the HHI should be applied to the market segment, where the number of possible players is virtually unlimited. Hence, to get a meaningful output for this index, we should aim to calculate a specific coefficient that would reflect the market specificity or adapt the range of $\mathrm{H}$-value outputs (defining dynamism) for the regulated markets with a limited number of players.

\section{References}

Aboubacry, D. (2014). Czech Technical University:Analýza úspěšnosti českých virtuálních operátorů dle oborů podnikání.

Brown, D. M., \& Warren-Boulton, F. R. (1988). Testing the Structure-Competition Relationship on Cross-Sectional Firm Data. Discussion paper, 88-96. Economic Analysis Group, U.S. Department of Justice. 
Capozza, D. R., \& Lee, S. (1996). Portfolio Characteristics and Net Asset Values in REITs. The Canadian Journal of Economics, 29, S520-S526.

Hirschman, A. O. (1964). The Paternity of an Index. The American Economic Review (American Economic Association).

Lucio, F., Juan, P. M. Ã., \& Yolanda, P. (2008). The evolution of mobile communications in Europe: The transition from the second to the third generation. Telecommunications Policy, 32, 436-449.

Mark, G. L. (2004). Adjusting the Herfindahl index for close substitutes: An application to pricing in civil aviation. Transportation Research Part E, 40,123-134.

Rimantas, S., \& Arūnas, B. (2011). Vilnius University, Lithuania: THE analysis of competition in cellular mobile telephone. Economics and Management Magazine.

Tirole, J. (1988). The Theory of Industrial Organization. MIT Press, Cambridge, MA.

US department of Justice (2010). Horizontal Meger Guidelines.

Xing, C., \& Geir, G. (2011). Development of competition indicators in the Norwegian general practice: Constructing a postal code specific Herfindahl Hirschman index a pplying STATA software. University of Oslo Health Economics Research Programme Working paper.

\section{Copyrights}

Copyright for this article is retained by the author(s), with first publication rights granted to the journal.

This is an open-access article distributed under the terms and conditions of the Creative Commons Attribution license (http://creativecommons.org/licenses/by/3.0/). 